\title{
A Metallurgic and Mechanical Differentiation to Friction Stir Welding (FSW)
}

\author{
M.A.H.M. Jasri, M. Afendi Rojan, M. Faizal Razak, Roslin Ramli
}

\begin{abstract}
The objective of this research was to measure the material properties as well as the forces to orthodox friction stir welding (FSW) performed in air of AA6061. These results were compared by using ultimate tensile strength (UTS) and weld root properties such as joint line residue length at the crossing point between the welded aluminum alloy which allows crack initiation. Metallurgic cross sections of the AA6061 welds were prepared and the weld nugget hardness between the welding parameters was compared as well. Experiments such as this one and others enumerating the forces and process parameters must be achieved. A steady state model of temperature distribution has been put forward and is shown to precisely forecast trends in heat input using heat generation equations from [1,2]. Temperature distribution was measured and correlated to data by use of Micron Thermal Imaging camera.
\end{abstract}

Index Terms: Friction stir welding, Tensile strength, Ttemperature distribution, Hardness, Grain size.

\section{INTRODUCTION}

Friction stir welding was developed and patented by a research team led by Wayne M. Thomas [1,2] of the Welding Institute in England. FSW is defined as a method for joining two or more materials where a tool, moving in a cyclic motion to the work pieces, enters the joint region, in the vicinity plasticizes it and moves along the the joint border thus causing a solid state joint between the work pieces [3].

A depiction of the friction stir welding process is shown below in figure 1 . It can be spotted that that, cause to the rotation of the tool, friction stir welding is an lop-sided process with aline to the joint line.

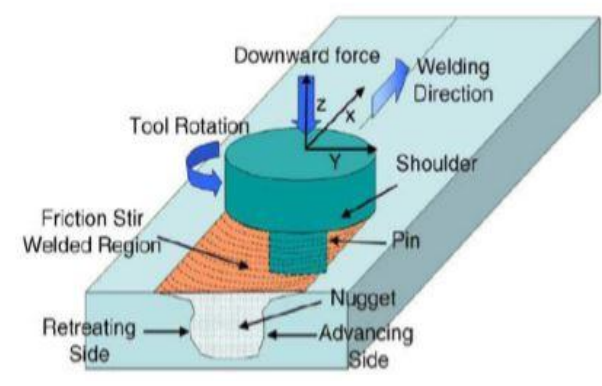

Fig. 1 Schematic of friction stir welding [4]

\section{LITERATURE REVIEW}

\section{Parameter Review}

Dispensation parameters for friction stir welding including rates of travel, rotation, and forces will be explained here. Thread uses welding speed as an substitute to traversing rate or traversing speed. Similarly, the rotational velocity of the tool is known as the tool rotation speed. Its direction of rotation, clockwise or counter-clockwise, is described when observing the tool from above.

The tool is defined as the rotating piece designed to generate heat, plastically deforming the weld material in order to form the bond. This definition is general as several tools exist with a floating, fixed, or stationary shoulder geometry thus producing no heat for the purposes of welding.

The probe is the part of the tool which is plunged below the surface of the work piece being welded. It can use either "pin-shaped" or straight depending on the application. The shoulder of the tool rests on the surface of the material being welded and may be plunged to some extent end surface of material. The shoulder is always of a smaller diameter than the probe.

\section{Weld Zone regions}

The advancing side and retreating side are important to shown out in the cross section of a weld. This is cause to the fact that friction stir welding is inherently an lop-sided process because of the rotational velocity and features of the tool.

The advancing side is the side of the weld which the rotational velocity component and traversing velocity component are beneficial. The retreating side is the side of the weld which the rotational velocity component and traversing velocity component are mining components.

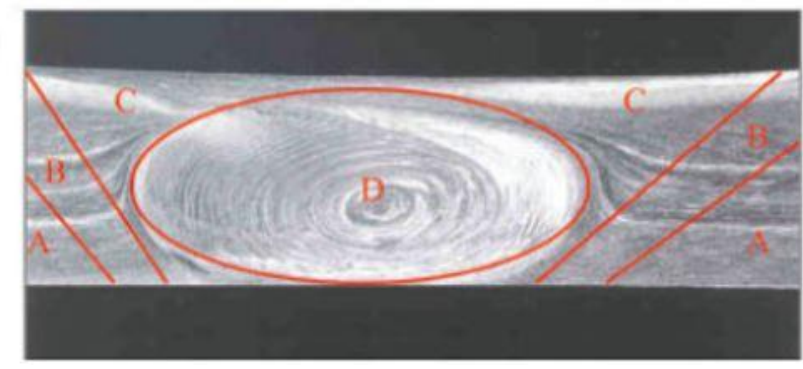

Fig. 2 Plain view of FSW Zone

Weld features and zones will be identified using the plan view illustrated in figure 2 . The four main zones are listed below and are labeled A, B, C, and D. These are the primary zones for describing the amount or lack of thermoplastic heating and mixing of the weld joint. The descriptions of the zones A-D are shown above.

The 'A' zone in the above figure is known as the parent material. This is the region farthest from the joint center line and has not been affected by heat or deformation. ' $\mathrm{B}$ ' zone is affected only by direct distribution heat and no plastic deformation is visible. 


\section{A Metallurgic and Mechanical Differentiation to Friction Stir Welding (FSW)}

This zone is known as the HAZ or heat affected zone which parallels fusion welding terminology. ' $\mathrm{C}$ ' zone is affected by direct heating and thermoplastic deformation. It is referred to as the TMAZ or thermo-mechanically affected zone. It generally relates to the section of the weld under the shoulder on the top to the pin radius on the bottom of the weld. The recrystallized structure is found in the fourth major ' $\mathrm{D}$ ' zone called the nugget. As a minimum the nugget is the region of densest mixing and therefore is start within a pin radius at least from the joint line of the weld. The TMAZ and nugget are both exposed to mixing and therefore can be difficult to separate in plane view sections. This is especially true in soft metals such as aluminum alloys which are used in the work.

\section{EXPERIMENT}

All ambient friction stir welding experiments were conducted using a Milwaukee \#2K Universal Milling Machine modified with a Kearney and Treker Heavy Duty Vertical Head Attachment at Vanderbilt's Welding Automation Laboratory.

The milling machine was modified in order to mechanize the welding process. This involved configuration the pulley ratios as suitable for welding at speeds and torques on different parameters. The experimental friction stir welding machine used at VUWAL is shown in figure 3.

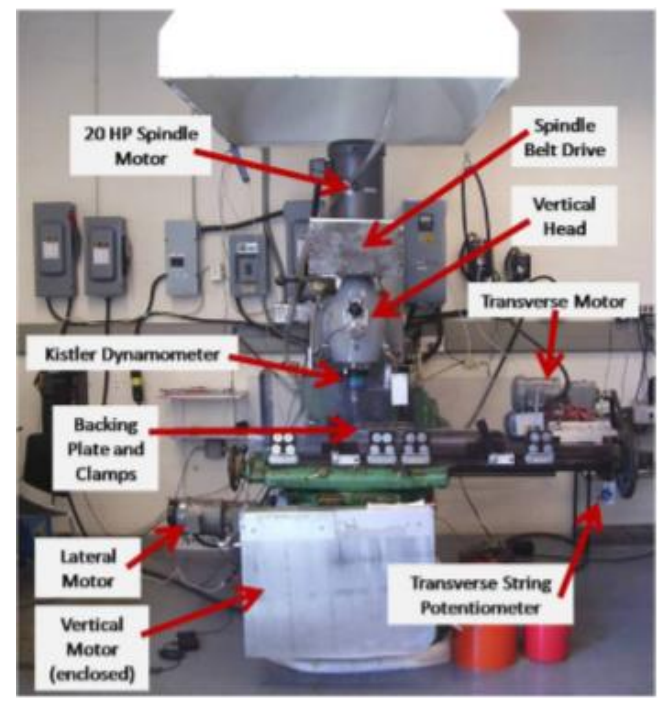

Fig. 3 FSW machine setup

\section{Parameter setup}

The pulley ratio used in this study was $4: 3$ and was set in order to under drive the spindle to lower speeds and higher torque. The maximum speed permitted by the motor was approximately $2300 \mathrm{rpm}$ at $60 \mathrm{~Hz}$ input. The traversal motor had an additional 11:2 pulley ratio supplementary to under drive the motor to a maximum allowable traverse speed of 16 ipm.

\section{Thermocouple Installations}

Welds in the Trivex tool probe study were implanted with type $\mathrm{K}, \mathrm{Al}-\mathrm{OH}$, thermocouples to define representative temperatures into the average as process started. It has been before perceived that the welding temperature at a cross location was not greatly affected by the traversal distance
$[4,5,6]$.

Multiple thermocouples were implanted to certify an accurate temperature reading. Four equally spaced thermocouples were placed into each weld at a thickness of $1 / 8$ ", or half the thickness of the $1 / 4$ " coupons, and a depth of 1.1875 ". This matched to the lateral position of the shoulder edge during welding.

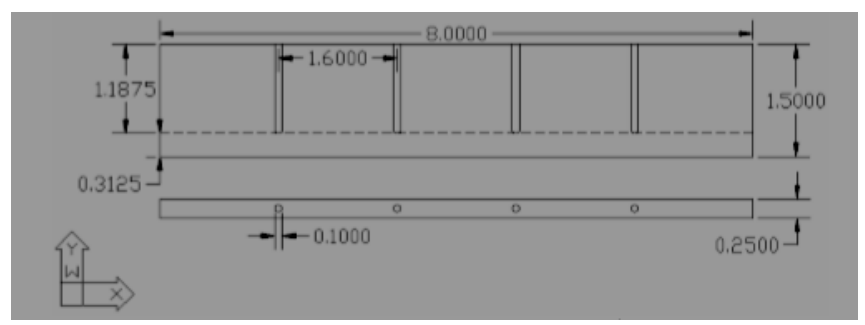

Fig. 4 Thermocople hole dimension

The diameter of the thermocouple hole was 1 inches or the nominal thickness of the thermocouple itself. The hole was filled with a colloidal silver thermal paste in order to make certain contact and maximum conductivity. This layout is shown in figure 4 above.

\section{RESULT AND CONCLUSION}

Optimal welds were run under ambient conditions from previous research [8]. These welds were found to have minimal joint line defects and high ultimate tensile strength (UTS). Optimal welds for welding process were determined by running a matrix which included rotational speeds of 2000, 2200, and $3000 \mathrm{rpm}$ as well as travel speeds of 10, 15, and $16 \mathrm{ipm}$.

Three tensile test coupons were cut from each weld to ensure the precision of the data. Test coupons were made to ASM specifications for tensile testing of a butt weld specimen. The geometry of the test coupon is shown in figure 5.

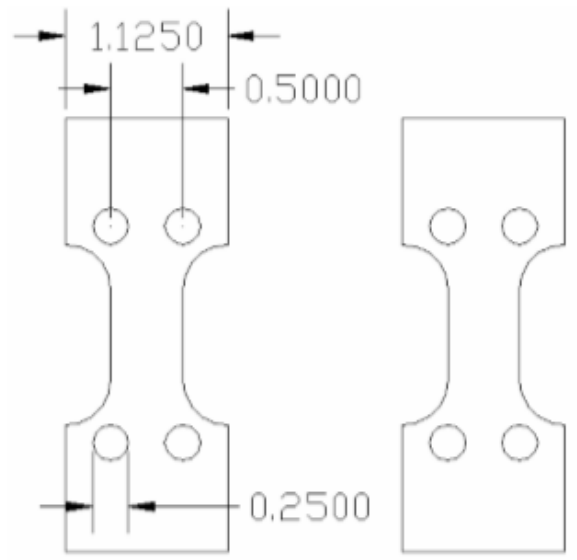

Fig. 5 Dimension of tensile specimen

The optimal welding conditions for FSW were found to be $2000 \mathrm{rpm}$ at $10 \mathrm{ipm}$. This linked to the greatest weld tensile strength of FSW parameters. The weld pitch of the optimal weld was found to be 200 revolutions per inch (rpi) for this matrix. 
The worm hole defect was discovered by tensile testing and occurred on the advancing side of the submerged weld 3000 rpm at $15 \mathrm{ipm}$, also at a weld pitch of $200 \mathrm{rpi}$. This is a verification of the weld pitch section.

The same weld pitch using different parameters gave bad weld quality in one of the two runs. All other welds were found satisfactory.

The speciemen fractured outside of the weld nugget and TMAZ in the weld heat affected zone (HAZ), an area of lower hardness than both the nugget and parent material due to the lack of mixing and dynamic recrystallization.

Cross sections were polished and etched using Boss's reagent at 10:1 ratio of water to hydrofluoric acid (HF) for 15-20 seconds. Weld zone cross sections showed a smaller heat affected zone and joint line remnant for FSW. Figure 6 shows the porosity generated in the FSW.

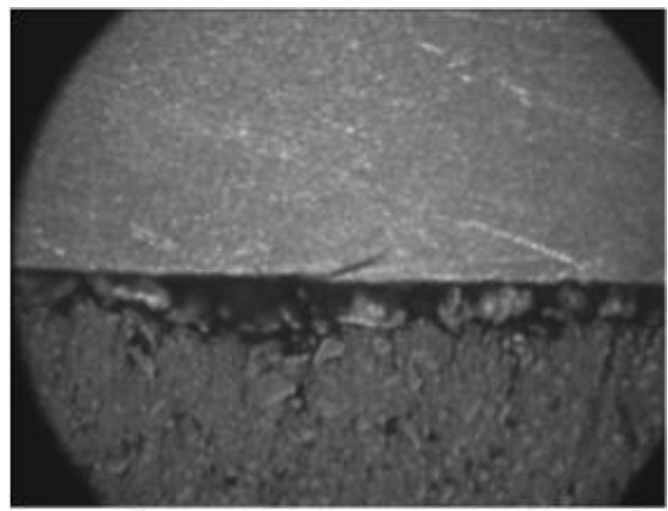

Fig. 6 Root flaw in FSW process (10x)

Tensile tests were run to determine the optimum weld parameters for FSW. Tests were conducted according to the ASM standard for materials testing. Ultimate tensile strength (UTS) was the standard for evaluation weld quality.

Optimal welds had welded to parent material UTS ratio was greater than $75 \%$. For the matrix given above, the optimal weld conditions for FSW were $2000 \mathrm{rpm}$ at $11 \mathrm{ipm}$ while the IFSW required $2000 \mathrm{rpm}$ at $8 \mathrm{ipm}$, a decrease of 3 ipm. Variants in parameters from the threaded probe experiment were due to the probe changing to Trivex. This leads to an increase in power to show the same forces.

The solution to the force reduction was a drop in travel speed to improve mixing and vertical flow. This is due to the power increase to form the bond. It is observed that a decrease in travel speed is required to increase the heat input into FSW's process.

For a constant travel speed (TS) it was observed that the weld quality increased with rotational speed (RS). This was observed mostly in FSW. It seem to indicate a logarithmic trend with respect to RS for the matrix run. For each TS run $(5,8,11 \mathrm{ipm})$ in the FSW matrix the trend for tensile strength vs. RS remained a logarithmic function of RS.

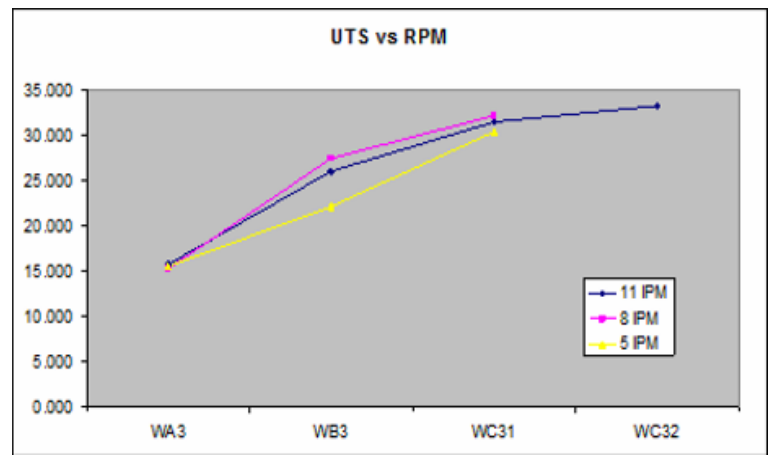

Fig. 7 UTS vs RPM

Figure 7 illustrates the logarithmic relationship between weld UTS vs. RPM. Results for a constant rotational speed showed independent UTS with increased TS.

The primary defects mode outside the optimal parameter wrapping was the wormhole defect. This is caused by a "cold" weld without sufficient heating of the joint and therefore a lack of mixing causes a tunneling defect near the root of the weld.

The threaded cylinder pin, as opposed to the others tool used in this study, created greater downward flow and higher forces leading to a larger envelope for IFSW.

Improvements in weld quality are made by FSW of the joint. In-situ heat treatment in the form of distributing heat gives the joint a better UTS and weld nugget hardness.

\section{REFERENCES}

1. Arbegast W. et al. "Friction Stir Spot Welding". 6th International Symposium on Friction Stir Welding. Session 4B. 2006.

2. Arbegast W. "A flow-partitioned deformation zone model for defect formation during friction stir welding”. Scripta Materialia. 58 (2008) 372- 376 .

3. Bloodworth T., Cook G., Strauss A. "Properties and forces of immersed friction stir welded AA6061-T6". 8th International Conference of Trends in Welding Technology. Pine Mountain, GA. (2008). 1-5.

4. Bunker E., Fleming P., Bloodworth T. "Friction Stir Welding Manual". Vanderbilt University Welding Automation Laboratory. 2007.

5. Clark T., "An analysis of microstructure and corrosion resistance in underwater friction stir welded 304L stainless steel". MS. Brigham Young University. 2005.

6. Colegrove P., Shercliff H. "Development of Trivex friction stir welding tool: Part 1 - two-dimensional flow modeling and experimental validation." Science and Technology of Welding and Joining. 9 (2003). 345-351.

7. Colegrove P., Shercliff H. "Development of Trivex friction stir welding tool: Part 2 - three-dimensional flow modeling". Science and Technology of Welding and Joining. 9 (2004). 352-361.

8. Crawford R. "Parametric quantification of friction stir welding". MS. Vanderbilt University. 2005.

9. Crawford R., "A mechanistic study of the friction stir welding process". PhD. Dissertation. Vanderbilt University. 2006.

10. Crawford R., Bloodworth T., Cook G., Strauss A. "High speed friction stir welding process modeling". 6th International Symposium on Friction Stir Welding. Saint Sauveur, Canada. 2006.

11. Dubourg L., Dacheux P. "Design and properties of FSW tools: a literature review". 6th International Symposium on Friction Stir Welding. Session 01 paper 62. 2006. 
A Metallurgic and Mechanical Differentiation to Friction Stir Welding (FSW)

\section{AUTHORS PROFILE}

Muhammad Azrie Husainy Bin Mohd Jasri is a program coordinator innovation of UniKL MIMET. $\mathrm{He}$ had actively winning a lot of innovation compotition either national or international such as i-compex, ITEX, MTE and I-envex. He consist making research about FSW process as manipulate the parameters and materials. 